\title{
Risk of cancer of the breast after legal abortion during first trimester: a Swedish register study
}

\author{
Britt-Marie Lindefors Harris, Gunnar Eklund, Olav Meirik, Lars Erik Rutqvist, Kerstin Wiklund
}

\begin{abstract}
An increase in induced abortions in Sweden has been accompanied by an increase in the incidence of breast cancer of about $40 \%$ in women aged $20-44$. To assess whether the apparent risk is real the risk of breast cancer was investigated in practically all Swedish women with a history of a legal abortion in the first trimester before the age of 30 during 1966-74 $(n=49000)$. The cohort was followed up in the Swedish cancer register to identify cases of breast cancer diagnosed more than five years after the abortion until the end of 1984 . The number of observed cases of breast cancer was 65 compared with an expected number of 84.5 , estimated from the contemporary Swedish population with due consideration to age, giving a relative risk of $0.8(95 \%$ confidence interval 0.58 to 0.99 ).
\end{abstract}

Contrary to most earlier reports, this study did not indicate any overall increased risk of breast cancer after an induced abortion in the first trimester in young women.

\section{Introduction}

Many epidemiological studies have investigated the risk of cancer of the breast in women who have had one or more abortions. ${ }^{1-21}$ Although the findings were not entirely consistent, most indicated increased risk.

Hypotheses regarding the possible association between abortions and an increased risk of breast cancer are based on the premise of incomplete differentiation of the cells in the glands of the breast during the first trimester. The changing concentrations of sex hormones during the second and third trimesters of pregnancy lead to increased differentiation of these cells. Interruption of a pregnancy during the first trimester causes an abrupt cessation of differentiation, which may result in a subsequent increase in the risk of breast cancer. ${ }^{22-25} \mathrm{~A}$ causal association between abortions and increased risk is also supported by experiments on animals. 22232627

The association is consistent with the observation that an increase in the number of induced abortions in Sweden (from about 2800 per year in 1960 to more than 30000 in $1974,{ }^{28}$ without any major change in the number of fertile women during the same period) was accompanied by an increase in the incidence of breast cancer of about $40 \%$ from 1961 to 1981 in women aged $20-44 .{ }^{29} \mathrm{An}$ increased risk if it were real would be of great concern as nowadays many women have a legal abortion; in Sweden there are more than 30000 legal abortions annually and about $40 \%$ of these women are nulliparous at the time of abortion. ${ }^{28}$

This study assessed the risk of breast cancer after abortion induced in the first trimester among women below 30 at that time.

\section{Subjects and methods}

Until 1975 legal abortion could be applied for in two ways in Sweden. Regardless of the method of application, all reports were stored in the archives of the National Board of Health and Welfare. Since January
1975, according to a new abortion law, there has been statistical but no individual registration of legal abortions.

For this study a computerised register was constructed from the 166840 application reports during 1966-74. Applications before 1966 were excluded because too many reports were incomplete. To preserve integrity of the data the computerised information was limited to identification number, county code, and a serial number for reference to the origina report. The identification number is unique to an individual person living in Sweden; it is composed of six digits based on date of birth, supplemented with a three digit serial number and a check digit and is not affected by changes in name or address.

A total of 34909 reports (21\% of all applications) did not have a complete identification number. By computerised linkage with countrywide population registers 26911 records were identified. Finally, 158842 records $(95 \cdot 2 \%$ of all applications) had a complete identification number: 92969 applicants had been born after 1936 (referred to as the total cohort), of whom 9336 had applied more than once during 1966-74.

Study cohort-Women from the total cohort were included in the study cohort if they fulfilled three criteria: age below 30 at the time of abortion, abortion performed during the first trimester of gestation (that is, within 90 days after the last menstrual period), and Swedish citizenship. (Immigrants tend to leave the country more frequently than Swedes, and a subsequent diagnosis of breast cancer would not be reported in Sweden.) The information was abstracted manually from the original reports.

Index abortion-An abortion as defined in the inclusion criteria was called an index abortion. A woman was not included in the study cohort if she had not had an index abortion, unless she had another legal abortion later during 1966-74 as defined in the inclusion criteria, which thus became the index abortion. The present study was a case-cohort study, based on incidence of breast cancer from the general population statistics ${ }^{29}$ and using the stratified ratio method. ${ }^{30}$ So far there are no official data in Sweden about the incidence of breast cancer regarding parity.

The number of women in the study cohort had to be estimated (appendix) because manual searches of records of the total cohort were too expensive. The total cohort was divided into four strata according to year of birth and general incidence of cancer of the breast in the different age ranges (table I). The precision of the estimated values was increased by using separate sample fractions drawn from each stratum by computerised random sampling; searches were performed for every record in the samples. (The number of sampled records for each stratum was at least four times that of the rough number of cases of breast cancer in each stratum, to ensure that the random errors from the samples would be much less than those among the cases.)

Women years at risk - In calculating women years at risk allowance was made for an induction period for cancer of five years, the most common period of latency 
shown in research on breast cancer, giving a follow up period from the fifth year after the year of the index abortion to the end of follow up - that is, 31 December 1984. (All women in the study cohort were assumed to be alive at the end of follow up, and all were under 48 at the end of follow up.) To assess risk of breast cancer immediately after a legal abortion calculations were also performed with an induction period for cancer of one year.

Expected number of cases of breast cancer was calculated in each stratum, based on its annual incidence in Sweden with regard to age and calendar year (appendix). Information on diagnosed cases of breast cancer was obtained by computerised linkage of records with the Swedish Cancer Register. The completeness of the registration of cases of breast cancer in Sweden is estimated at $98 \cdot 2 \% .^{31}$

Observed number of cases of breast cancer - The search was made for every woman in the total cohort who had breast cancer diagnosed after the index abortion; women who fulfilled the inclusion criteria in whom breast cancer was diagnosed at least five years after the abortion constituted the observed number of cases of breast cancer.

TABLE I-Data on total cohort and strata according to year of birth

\begin{tabular}{|c|c|c|c|c|c|}
\hline & $\begin{array}{l}\text { Stratum } 1 \\
(1937-42)\end{array}$ & $\begin{array}{c}\text { Stratum } 2 \\
(1943-6)\end{array}$ & $\begin{array}{l}\text { Stratum } 3 \\
(1947-50)\end{array}$ & $\begin{array}{l}\text { Stratum } 4 \\
(1951-60)\end{array}$ & Total \\
\hline $\begin{array}{l}\text { No }(\%) \text { of women in total } \\
\text { cohort }\end{array}$ & $7788(8)$ & $20735(22)$ & $26525(29)$ & $37921(41)$ & 92969 \\
\hline $\begin{array}{l}\text { Estimated No (\%) of eligible } \\
\text { women in study cohort }\end{array}$ & $2400(5)$ & $10800(22)$ & $12600(26)$ & $23200(47)$ & 49000 \\
\hline $\begin{array}{l}\text { Rough No (\%) of observed } \\
\text { cases of breast cancer }\end{array}$ & $43(29)$ & $60(40)$ & $32(21)$ & $14(9)$ & 149 \\
\hline $\begin{array}{l}\text { No }(\%) \text { of eligible observed } \\
\text { cases of breast cancer }\end{array}$ & $11(17)$ & $31(48)$ & $14(22)$ & $9(14)$ & 65 \\
\hline $\begin{array}{l}\text { Estimated No (\%) of women } \\
\text { years at risk }\end{array}$ & $27200(7)$ & $93900(24)$ & $105300(26)$ & $172900(43)$ & 399300 \\
\hline $\begin{array}{l}\text { Estimated No of expected } \\
\text { cases of breast cancer }\end{array}$ & $15 \cdot 38$ & $35 \cdot 07$ & $22 \cdot 62$ & $11 \cdot 43$ & \\
\hline \multirow[t]{2}{*}{$\begin{array}{l}\text { Estimated proportions of } \\
\text { nulliparous women }\end{array}$} & $0 \cdot 18$ & $0 \cdot 28$ & 0.52 & 0.91 & \\
\hline & & Samples & & & \\
\hline No of women in each sample & 174 & 240 & 128 & 201 & \\
\hline $\begin{array}{l}\text { No of eligible women in each } \\
\text { sample }\end{array}$ & 54 & 125 & 61 & 123 & \\
\hline $\begin{array}{l}\text { Expected No of cases of breast } \\
\text { cancer in each sample }\end{array}$ & 0.3456 & 0.4072 & $0 \cdot 1093$ & 0.0606 & \\
\hline
\end{tabular}

TABLE II-Risk of developing cancer of the breast after legal abortion according to parity

\begin{tabular}{lcccc}
\hline \multicolumn{1}{c}{$\begin{array}{c}\text { Parity at time of } \\
\text { index abortion }\end{array}$} & $\begin{array}{c}\text { Observed No of cases } \\
\text { of breast cancer/ } \\
\text { expected No of cases }\end{array}$ & Relative risk & $\begin{array}{c}95 \% \text { Confidence } \\
\text { interval }\end{array}$ & $\begin{array}{c}\text { Estimated No of } \\
\text { women years at risk }\end{array}$ \\
\hline $\begin{array}{l}\text { Nulliparous } \\
\text { Parous }\end{array}$ & $34 / 31.22$ & 1.09 & 0.71 to 1.56 & 240000 \\
\hline All & $31 / 53.29$ & 0.58 & 0.38 to 0.84 & 160000 \\
\hline
\end{tabular}

TABLE III - Summary comparison of findings of studies on risk of breast cancer after abortion

\begin{tabular}{|c|c|c|c|c|}
\hline Study & Relative risk & Significant & $\begin{array}{l}\text { Induced abortion } \\
\text { separately }\end{array}$ & $\begin{array}{l}\text { Defined maximum length } \\
\text { of pregnancy } \\
\text { (months) }\end{array}$ \\
\hline Salber $e t a l^{\prime}$ & 1 & No & No & ND \\
\hline Valaoras et $a l^{2}$ & $>1$ & Yes & No & ND \\
\hline Lin $e t a l^{3}$ & $>1$ & Yes & No & 4 \\
\hline Lowe and MacMahon ${ }^{4}$ & & No & No & ND \\
\hline Yuasa and MacMahon' & $>1$ & Yes & No & ND \\
\hline Ravnihar et al & $<1$ & No & No & ND \\
\hline Stavraky and Emmons & $>1$ & No & No & ND \\
\hline Soini $^{R^{2}}$ & $>1$ & Yes & No & ND \\
\hline Choi $e t a l^{4}$ & $>1$ & Yes & No & 4 \\
\hline Paffenbarger $e t a l^{\prime \prime \prime}$ & & No & No & ND \\
\hline Paffenbarger $e t a l^{\prime \prime}$ & $<1$ & No & No & 6 \\
\hline Toti et al $l^{12}$ & $>1$ & No & No & ND \\
\hline Kelsey et al ${ }^{13}$ & $>1$ & No & No & ND \\
\hline Pike et al ${ }^{14}$ & $>1$ & Yes & Yes & 3 \\
\hline Brinton et al ${ }^{\prime \prime}$ & $>1$ & No & No & 3 \\
\hline Helmrich et $a l^{\text {th }}$ & 1 & No & No & ND \\
\hline Hirohata et alli & $>1$ & No & Yes & ND \\
\hline LaVeccia et a $l^{1 \times}$ & 1 & No & Yes & ND \\
\hline Ewertz and Duffy ${ }^{14}$ & $>1$ & Yes & Yes & 3 \\
\hline Rosenberg et $a^{20}$ & $>1$ & No & Yes & 6 \\
\hline Howe et al $l^{11}$ & $>1$ & Yes & Yes & 5 \\
\hline Present study & $<1$ & Yes & Yes & 3 \\
\hline
\end{tabular}

The ratio between the observed and the expected number of breast cancer cases constituted the relative risk. Different methods were used for estimating variances (appendix).

The maximum follow up periods for the study cohort were 6-8 years (33000 women), 9-11 years (11000), and 12-14 years (5000).

Of the study cohort, $41 \%$ of women were nulliparous at the time of the index abortion. The corresponding figure in the general population during the same period in the same age groups was $49 \%$.

To study whether the risk of breast cancer increased during the first years after a full term pregnancy in young women the data were analysed for an induction period of one year. Some epidemiological studies have indicated that the risk of breast cancer depends on the total number of abortions or the number before first full term pregnancy, or both. ${ }^{3815}$ Because of small numbers $2940(6 \%)$ of the study cohort and $603(3 \%)$ of the nulliparas had had an induced abortion before the index abortion) further analyses of the number of abortions were not expected to increase the power of testing of the main hypothesis.

\section{Results}

The observed number of cases of breast cancer among all women in the study cohort was 65 compared with an expected number of $84 \cdot 5$. The corresponding ralative risk was 0.77 (significant at $\mathrm{p}<0.05$, table II). The lowest relative risk $(0.58)$ was observed among the women who were parous at the time of the index abortion; the risk among women who were nulliparous $(1.09)$ was significantly higher $(\mathrm{p}<0.05)$ (table II).

Analyses with an induction period for cancer of only one year showed 71 observed cases of breast cancer (36 in nulliparous women) and 93.57 expected cases (33.61 in nulliparous women), which gave almost the same point estimates of relative risk (nullipara 1.07, para 0.60 , and overall 0.76 ) as an induction period of five years. Thus the present study suggested no major changes in the risk of breast cancer during the first years after an abortion in the first trimester compared with later.

\section{Discussion}

Table III summarises the differing results from earlier epidemiological studies. In all but one ${ }^{21}$ a retrospective interview or questionnaire technique was used. In two the possibility of recall bias in what is a sensitive subject was discussed. ${ }^{21}$

Whether our observed difference in the risk of breast cancer between nulliparous and parous women may be attributed to the postponement of a first birth by the nulliparous women or to a differing effect of termination of an early pregnancy could not be determined from the data available as we did not have information about age in possible cases of a first birth after the index abortion, a variable reported to influence the risk of breast cancer in premenopausal women. ${ }^{32-35}$

The present study included only legally induced abortions - that is, interruption of a healthy pregnancy. Furthermore, the proportion of women in the Swedish population who had had spontaneous abortion, assuming the same age distribution as that of the study cohort at the time of the index abortion, was estimated at less than $0 \cdot 1 .{ }^{36}$ Women who had had an illegal abortion were not identifiable from the data. The incidence of illegal abortions in Sweden in the early 1960 s was estimated at $2-4 \%$ of all recorded pregnancies. ${ }^{36}$ In the mid-1960s improved contraception (with the introduction of the contraceptive pill and permitted use of intrauterine devices) combined with more liberal interpretations of the law regulating 
abortions considerably decreased the number of illegal abortions, as occurred in the United States. ${ }^{37}$

The general population statistics were based on all Swedish women, including the women in the study cohort. A possible contribution from this cohort to the general incidence of breast cancer would shift the relative risks in the present study towards unity. Our results, however, showed significantly decreased risks for women with $100 \%$ exposure to induced abortion.

The short follow up in the study is a limitation; only 5000 of the women in the study cohort were followed up for more than 11 years after the induction period. It would therefore be appropriate to perform a similar linkage with the cancer register and subsequent analysis in five, 10 , or 20 years.

The design of this study differed from those of previous epidemiological studies on breast cancer in that it was based on a cohort; data were available from almost all $(95 \cdot 2 \%)$ Swedish women who applied for legal abortion during 1966-74; information regarding the abortions was reported from the hospitals at the time of the abortion, following mandatory requirements, and not from the women by interview; data on the incidence of breast cancer in the general Swedish population were obtained from the National Cancer Registry (whose completeness of registration of breast cancer in women has been estimated at $98 \cdot 2 \%$ ); and an induction period for cancer of five years was allowed Most of the earlier epidemiological studies showed increased risk among women who had had an abortion; one reason for this could be recall bias. A woman with cancer is perhaps more likely to remember and report a previous abortion than a healthy control, ${ }^{221}$ and as data in the case-control studies were collected by interview or questionnaires ${ }^{1-20}$ recall bias may have influenced their results.

In the original records there was no information about confounding factors such as smoking and family history of cancer, and notes regarding taking of the contraceptive pill, education, and economics were incomplete. Marital state was given but was most probably changed for most of the young unmarried women. These confounding factors have not been considered in analyses of abortions in previous studies, with which our results were compared. If any of them, which increased the risk of breast cancer, were more common among women who have had induced abortion they would tend to change our results towards unity.

This study was supported by grants from King Gustav V's Jubilee Fund, Stockholm, and Family Health International, NC 27709, United States.

\section{Appendix}

The number of women in the study cohort $(N)$ was calculated from each stratum i according to the formula:

$$
\mathrm{N}=\Sigma \mathrm{N}_{\mathrm{i}}=\Sigma\left(\mathrm{M}_{\mathrm{i}}{ }^{\star} \mathrm{n}_{\mathrm{i}} / \mathrm{m}_{\mathrm{i}}\right)
$$

The expected number of breast cancer cases $\left(E_{i}\right)$ was calculated in each stratum from the estimated number of women years at risk, with indirect standardisation and adjustment for age and calendar year according to the formula:

$$
\mathrm{E}_{\mathrm{i}}=\mathrm{f}_{\mathrm{i}}^{\star} \sum \mathrm{e}_{\mathrm{ik}} \text {, }
$$

where $f_{i}=\left(M_{i}-C_{i}\right) / m_{i} ; k$ denotes the number of women sampled in the relevant stratum and ranges from 1 to $n_{i}$ for stratum $i$; and $e_{i k}$ is the cumulated expected individual incidence with due regard to age and calendar year.

Variances estimated by different methods-Observed numbers were assumed to follow a Poisson distribution. Expected numbers in each stratum were calculated according to Cochran ${ }^{38}$ :

$$
\mathrm{V}\left(\mathrm{E}_{\mathrm{i}}\right) \approx \mathrm{N}_{\mathrm{i}}^{2 \star} \mathrm{s}_{\mathrm{i}}^{2 \star}\left(1-\mathrm{m}_{\mathrm{i}} / \mathrm{N}_{\mathrm{i}} / \mathrm{m}_{\mathrm{i}}\right.
$$

where $s_{i}^{2}=\left\{\Sigma\left(e_{i k}^{2}\right)-\left(\sum e_{i k}\right)^{2} / m_{i}\right\} /\left(m_{i}-1\right)$.

$\Sigma e_{i k}$ is the sum of expected numbers of the $n_{i}$ cases in sample number $\mathrm{i}$ and $\Sigma\left(\mathrm{e}_{\mathrm{i}}{ }^{2}\right)$ is the sum of squares of the individual expected values of the $\mathrm{n}_{\mathrm{i}}$ cases.

Variance for relative risk was calculated using Gauss approximation formulas ${ }^{39}$ (presuming that observed $(\mathrm{O})$ and expected

(E) cases were not correlated): $\mathrm{V}(\mathrm{O} / \mathrm{E}) \approx \mathrm{V}(\mathrm{O}) / \mathrm{E}^{2}+\mathrm{V}(\mathrm{E})^{\star} \mathrm{O}^{2} / \mathrm{E}^{4}$

where $\mathrm{V}\left(\Sigma \mathrm{E}_{\mathrm{i}}\right)=\Sigma \mathrm{V}\left(\mathrm{E}_{\mathrm{i}}\right)$

1 Salber EJ, Trichopoulos D, MacMahon B. Lactation and reproductive histories of breast cancer patients in Boston, 1965-1967. INCI 1969;43: 1013-24.

2 Valaoras VG, MacMahon B, Trichopoulos D, Polychronopoulou A. Lactation and reproductive histories of breast cancer patients in greater Athens, 1965 -

3 Lin TM, Chen KP, MacMahon B. Epidemiologic characteristics of cancer of the breast in Taiwan. Cancer 1970;27:1497-504.

4 Lowe $C$ MacMahon B. Breast cancer and reproductive history of women in South Wales. Lancet 1970;i:153-6.

5 Yuasa S, MacMahon B. Lactation and reproductive histories of breast cancer patients in Tokyo, Japan. Bull WHO 1970;42:195-204.

6 Ravnihar B, MacMahon B, Lindtner I. Epidemiologic features of breast cancer in Slovenia, 1965-67. Eur f Cancer 1971; 7:295-306.

7 Stavraky K, Emmons S. Breast cancer in pre-menopausal and post-menopausal women. $\mathcal{F N C I} 1974 ; 53: 647-54$

8 Soini I. Risk factors of breast cancer in Finland. Int $f$ Epidemiol 1977;6:365-73.

9 Choi NW, Howe GR, Miller AB, et al. An epidemiologic study of breas cancer. Am $\mathcal{A}$ Epidemiol 1978;107:510-21.

10 Paffenbarger RS Jr, Greenberg LM, Chang H-G, Kampert JB. Epidemiologic characteristics of breast cancer in three menopausal stages. Preliminary findings. National Cancer Institute Monographs 1979;53:195-202.

11 Paffenbarger RS Jr, Kampert JB, Chang H-G. Characteristics that predict risk of breast cancer before and after the menopause. Am J E Eidemiol 1980;112: 258-68.

12 Toti A, Piffanelli A, Pavanelli T, et al. Possible indication of breast cancer risk through discriminant functions. Cancer 1980;46:1280-5.

13 Kelsey JL, Fischer DB, Holford TR, et al. Exogenous estrogens and other factors in the epidemiology of breast cancer. $7 N C I$ 1981;67:327-33.

14 Pike MC, Henderson BE, Casagrande JT, Rosario I, Gray GE. Oral contraceptive use and early abortion as risk factors for breast cancer in young women. Br J Cancer 1981;43:72-6.

15 Brinton LA, Hoover R, Fraumeni JF Jr. Reproductive factors in the aetiology of breast cancer. Brf Cancer 1983;47:757-62.

6 Helmrich SP, Shapiro S, Rosenberg L, et al. Risk factors for breast cancer. Am f Epidemiol 1983;117:35-45.

17 Hirohata T, Shigematsu T, Nomura A, Nomura Y, Horie A, Hirohata I. Occurrence of breast cancer in relation to diet and reproductive history: case-control study in Fukuoka, Japan. National Cancer Institute Monograph 1985;69:187-90.

18 LaVeccia C, Decarli A, Parazzini F, et al. General epidemiology of breast cancer I. Parity. Am J E pidemiol 1987;16:347-55.

19 Ewertz M. Duffy SW Risk of breast cancer in relation to productive factors in Denmark. Brf Cancer 1988;58:99-104.

20 Rosenberg L, Palmer JR, Kaufman DW, Strom BL, Schottenfeld D, Shapiro $S$. Breast cancer in relation to the occurrence and time of induced and spontaneous abortion. Am f Epidemiol 1988;127:981-9.

21 Howe HL, Seine RT, Bzduch H, Herzfeld P. Early abortion and breast cance risk among women under age 40. Int $\mathcal{F}$ Epidemiol 1989;18:300-4.

22 Russo J, Tay LK, Russo IH. Differentiation of the mammary gland and susceptibility to carcinogenesis. British Cancer Research and Treatmen $1982 ; 2: 5-73$.

23 Little JB, Hahn GM. Life-cycle dependence of repair of potentially lethal radiation demage. Int f Radiat Biol 1973;23:401-7.

24 Petrakis NL. Genetic cerumen type, breast secretory activity and breast cance epidemiology. Genetics of Human Cancer 1977;26:297-300.

25 Petrakis NL. Cerumen genetics and human breast cancer. Science 1971 173:347-9.

26 Russo J, Russo IH. DNA labeling index and structure of the rat mammary gland as determinants of its susceptibility to carcinogenesis. $¥ N C I$ 1978;61: $1451-9$

27 Nagasawa H, Yanai R. Frequency of mammary cell division in relation to age: its significance in the induction of mammary tumors by carcinogen in rats. INCI 1974;52:609-10.

28 National Board of Health and Welfare. Abortions 1975-1983. Statistics of the National Board of Health and Welfare. Stockholm: National Board of Healt and Welfare, 1977-84.

29 National Board of Health and Welfare. Cancer incidence in Sweden 1971-1984 Stockholm: National Board of Health and Welfare, 1987.

30 Wacholder S, Boivin J-F. External comparisons with the case-cohort design Am f Epidemiol 1987;126:1198-209.

31 Mattsson B, Wallgren A. Completeness of the Swedish cancer register. Acto Radiologica (Oncology) 1984;23:305-13.

32 MacMahon B, Cole P, Brown J. Etiology of human breast cancer: a review. $7 N C I 1973 \cdot 50: 21-39$.

33 Lipnick R, Speiser FE, Bain C, et al. A case-control study of risk indicator among women with premenopausal and early postmenopausal breast cancer Cancer 1984;53:1020-4.

$34 \mathrm{Kvåle} \mathrm{G,} \mathrm{Heuch} \mathrm{I,} \mathrm{Eide} \mathrm{GE.} \mathrm{A} \mathrm{prospective} \mathrm{study} \mathrm{of} \mathrm{reproductive} \mathrm{factors} \mathrm{and}$ breast cancer. I. Parity. Am f E pidemiol 1987;126:831-41.

$35 \mathrm{Kvåle} \mathrm{G}$, Hench I. A prospective study of reproductive factors and breast cancer. II. Age at first and last birth. Am $\mathcal{F}$ E pidemiol 1987;126:834-50.

36 Pettersson F. Epidemiology of early pregnancy wastage [Dissertation] Uppsala: University of Uppsala, 1968. $125 \mathrm{pp}$

37 Cates W, Jr. Legal abortion: the public health record. Science 1982;215: $1586-90$.

38 Cochran WG. Sampling techniques. New York: John Wiley, 1963.

39 Blom G. Probability and statistics: theory and applications. Berlin, New York: Springer Verlag, 1989:123.

(Accepted 5 October 1989) 